\title{
School-based Multi-component Intervention. Symptoms of Iranian ADHD Children
}

\author{
Sepideh Shaban ${ }^{1}$, Maznah Baba ${ }^{1}$, Sidek Mohd Noah ${ }^{1} \&$ Wan Marzuki Wan Jaafar ${ }^{1}$ \\ ${ }^{1}$ Department of Counselor Education and Counseling Psychology, Faculty of Educational Studies, Universiti \\ Putra Malaysia, Malaysia \\ Correspondence: Sepideh Shaban, Department of Counselor Education and Counseling Psychology, Faculty of \\ Educational Studies, Universiti Putra Malaysia, Selangor, 43300, Malaysia. Tel: 60-16-686-1303. E-mail: \\ shaban.6066@yahoo.com
}

Received: October 23, 2014 Accepted: December 30, 2014 Online Published: April 20, 2015

doi:10.5539/ass.v11n10p212 URL: http://dx.doi.org/10.5539/ass.v11n10p212

\begin{abstract}
The present study evaluated the effectiveness of school-based multi-component intervention that implemented for ADHD school-aged children specially. Participants were 64 school-aged ADHD children that randomly assigned in two study groups including one experimental and one control group. Teachers of these children were invited to participate in the teacher training. Teachers took part in 8 sessions teacher training that involved contingency management, cognitive behavioral strategies and class management instructions for managing of ADHD children. Members of the control group didn't receive any program. Dependent measures included parent and teacher's ratings of inattention, hyperactivity/impulsivity and ADHD symptoms. Information for the study achieved in three pre-test, post-test and follow-up levels. Parents and teachers in experimental group reported significantly less inattention, hyperactivity/impulsivity symptoms in children at home and school respectively rather than before conducting the program. Findings of the study showed similar effect of school-based multi-component intervention on all symptoms of inattention, hyperactivity/impulsivity across home and school. Results of the present study provided some supports for effectiveness of school-based multi-component program on symptoms of ADHD in school-aged children in Iran.
\end{abstract}

Keywords: school-based multi-component intervention, ADHD children, ADHD symptoms

\section{Introduction}

Children with Attention Deficit Hyperactivity Disorder (ADHD) have recognized by two main symptoms including, inattention, and hyperactivity/impulsivity (American Psychiatric Association, 2013; Barkley, 2000). This disorder has considered as a major public health concern and most of the time, symptoms of this disorder remain until adulthood. This disorder that commonly presenting in childhood has three subtypes: predominantly hyperactive-impulsive, predominantly inattentive, and combined (American Psychiatric Association, 2013). Because of the high prevalence of ADHD this disorder considered as a main contributor in children and their caregivers life (Hodgson, Hutchinson, \& Denson, 2012). During last decades large amount of studies supported this hypothesis that children with ADHD have deficit in self-regulation. This inability can lead to the second deficits including information processing, inhibition of response, arousal, alertness, planning, executive functioning, meta-cognition and self-monitoring (Biederman et al., 2008). All previous findings approved that children with ADHD have cognitive and behavioral problems that need an essential note (Miranda, Presentacia, \& Soriano, 2002). Moreover, high prevalence of this disorder among school-aged children in Iran (Khooshabi \& Puretemad, 2002), and lack of enough attention for this children specially for school problems (Noori, 2010) indicated to their dire need for applying appropriate interventions for these children in Iran.

Stimulant medication as the most widely used treatment has a higher impact rate than psychosocial interventions, however it's not quiet acceptable for parents because of some side effects such as weight loss, shakiness, nausea, gas, diarrhea and so on (Donnelly, Haby, Carter, Andrews, \& Vos, 2004; Peterson, McDonagh, \& Fu, 2008). Although, previous studies demonstrated that improvement in attentiveness and interpersonal interactions with parents, teachers, classmates and peers but there is no evidence for improvement of academic performance and cognitive abilities in same levels by stimulant medication. Moreover, simultaneous medication doesn't seem to show long term changes on behavioral problems of children with ADHD (Pelham et al., 1988). Mentioned 
limitations for pharmacotherapy showed necessity of having psychosocial interventions as another choice for treatment of these children `s symptoms.

Children with ADHD is characterized as having deficiency in behavioral inhibition and cognitive instruction (Barkley, 2003). As was described by Barkley (2003) these children have difficulty with accomplishing the goal-directed behaviors, problem solving and planning. All these problems lead to awful school and social outcomes that illustrate importance of context which intervention is implementing, that play a main role as the developmental course of children's behavior implement in a complex context with social influence (Miranda et al., 2002). School provides a social network that needs high degree of control, planning and evaluation. Moreover, in school, children spend considerable time. In the class children have expanded version of relationship with their classmates and teacher. Moreover, children have to participate in the learning process in the class and need to involve actively with classwork without interrupting others. Thus school is an appropriate place to prepare an intervention to develop self-regulation (Atkins, Graczyk, Frazier, \& Abdul-Adil, 2003; Miranda et al., 2002).

During last decade large amount of studies addressed effectiveness of psychosocial treatments for ADHD children. These studies mentioned the effectiveness of psychosocial intervention on ADHD symptoms and other behavioral problems (Miranda, Jarque, \& Rosel, 2006; Miranda, Presentación, Siegenthaler, \& Jara, 2011; Pelham \& Fabiano, 2008). Previous research applied two approaches of psychosocial interventions including contingency management and cognitive strategies. In the contingency management strategies, teachers learn to apply some techniques in the class including positive reinforcement, token reward, time out and response cost. These techniques can help teachers to have more control among children's behavior but not in academic performance (Miranda et al., 2002; Pelham, Wheeler, \& Chronis, 1998). Also teachers can be equipped by cognitive behavioral strategies that promote children`s ability in self-control such as self-monitoring, self-statement, self-evaluation and self-reinforcement. Moreover, students with ADHD experience large amount of difficulties in classroom that highlight the essential need for instructional management in class in addition to contingency management and self-management (cognitive strategies). All these techniques reduce maladaptive behaviors of children, also these strategies decrease the hyperactivity/impulsivity and aggressiveness in children with ADHD though there are no change in academic records. Up to these techniques, children need to have an especial instruction in the class performance to be adapted by learning rules in the class.

As children with ADHD in Iran have to participate in mainstream schools, teachers need learn about this children and about the use of management strategies for them. Most of the studies have conducted on ADHD children assessed using of simultaneous medication for this children with and without psychosocial interventions (Hooshvar, Behnia, Khooshabi, Mirzayi, \& Rahgozar, 2009; Khooshabi \& Roshanbin, 2009). There is no documents regarding working with ADHD children directly or non-directly in mainstream schools. In this regard, this study consider to apply the program that developed by Miranda et al. (2002) in University of Valencia and Castellon in Spain. Although this program applied the natural setting to improve children `s behavior, it used a multi-component design to improve some of behavioral problems of children. This program simultaneously applied behavioral, instructional and cognitive strategies in class for ADHD children. This multi-component program organized for teachers of ADHD children in mainstream schools with the aim of promoting teachers management skills in a class.

The purpose of this study was to examine the effectiveness of school-based multi-component intervention on symptoms of children with ADHD. Previous research indicated to effectiveness of this intervention on behavioral problems of ADHD. In the present study this intervention applied for Iranian children with ADHD. This approach seems to be more effective than previous interventions that characterizes as multi approach intervention.

\section{Method}

This study applied true experimental design with randomized pre-test post-test control group design on Iranian children with ADHD. Children in the present study were assigned randomly to one of the two condition: (1) school-based multi-component group which consists of the eight week intervention for teachers or (2) group without intervention. Number of 64 children was chosen randomly from 143 of children with ADHD from ten mainstream schools. These children referred to mental health clinic for ADHD children. They were introduced to the clinic by principals of schools in order to be assessed by clinicians. Primary assessment was performed by a psychologist and in the next step psychiatrists assessed all children. Parents and teachers of these children participated in an interview that implemented by a clinical psychologist. All these process was conducted across three clinics. There were some inclusion and exclusion criteria for children in the study. The main inclusion 
criteria were as follow: (1) children with ADHD combined type, (2) children in age range from 9-11 and the main exclusion criteria were: (1) children with learning disorders, (2) children with any history of medication and any other treatment, (3), ADHD children with any co-morbidity problems. Number of 102 children were recognized as children with ADHD combined type in age range from 9-11, without any comorbidity and learning problems. Afterward, researcher selected 64 students randomly. In the next stage, all teachers of these children were invited to the introduction session to be familiar with the research process and signed the consent form for participating in the study.

\subsection{Assessment Information}

Children, parents and teachers underwent in a broad multimodal assessment that is part of a standard procedure of a counseling - clinic for children with behavioral and emotional problems. Parents took part in an unstructured interview to obtain information about family, social and medical history and they were asked to complete several child behavior checklists for their children and some psychopathological tests. Teachers completed two child behavior checklists and took part in an interview. Furthermore, a classroom observation was conducted, and child's symptom severity was assessed by clinical ratings.

\subsection{Treatment and Control Condition}

After assessment process number of 32 children with ADHD set aside for experimental group and 32 children in control group. Parents and teachers of these children took part in a session to obtain some information regarding the study. Parents in the control group were asked to read some information regarding ADHD and behavioral parent training that were collected in a manuscript. Teachers in the experimental group participated in eight, three hours sessions of school-based multi-component intervention. None of the participants in the control group experienced any intervention already. Teacher training sessions allocated to contingency management strategies and techniques for enhancing the self-control and instructional management strategies in the class.

\subsection{School-based Multi-component Intervention}

This program developed by (Miranda, Presentacia, \& Soriano, 2002) consists of eight, three hours sessions that implemented during eight weeks. Teachers in this program learned about management strategies for students with ADHD in their class. The content of the sessions were reinforcement, response cost, instructional management, and self-control, self-evaluation and self-encouragement strategies. During the last two sessions teachers were asked to apply the strategies in the class and assess the problems that they had during implementing the strategies.

\subsection{Semi-structured Interview}

Researcher applied a semi-structured interview with participated teachers in the study. Five teachers mentioned the advantages of short-term implementation of the study with high amount of information they achieved during sessions. Another main field that teachers indicated was group based format of this program. Teachers became aware about different aspects of ADHD difficulties in behavioral and academic fields. Most of the teachers mentioned that the program is applicable for all students in the class. Almost all teachers believed on effectiveness of instructional management strategies in class especially for ADHD students. They mentioned that this approach of the program prepared an appropriate context for more on-task behavior. Some teachers even reported more academic achievement for ADHD children.

\subsection{Measures}

This study aimed to measure effectiveness of school-based multicomponent intervention on symptoms of children with ADHD. In this regard this study applied two measures for parents and teachers of children including Children Symptom Inventory (CSI4) and Teacher Report Form (TRF) respectively. Both measures implemented through three sessions in pre-test, post-test and follow-up. A demographic questionnaire that designed by researcher was implemented to obtain information on family social, economic and educational level.

\subsection{Children Symptom Inventory}

Child symptom inventory was used to measure behavioral and emotional problems of children. These instruments have parent and teacher form in order to assess their point of view at home and school settings respectively for age 5-12. This study aimed to measure three category of children 's problem including ADHD Inattentive type (ADHD I, 9 items), ADHD hyperactive/impulsive type (ADHD HI, 9 items) and ADHD combined type (ADHD C, 18 items). Mohamad Esmayil (2001), has adapted CSI4 in Tehran/Iran for age 6-11. In Iran, the content validity of CSI-4 was conducted by nine psychiatrists, and they were asked to judge about appropriateness and correlation between each question with the particular definition of instrument. All nine 
psychiatrists accepted the high ability of this instrument on separation of emotional and behavioral problems of children.

\subsection{Teacher Report Form}

Teacher report form aims to obtain teachers perception toward behavioral and academic problems of teachers. This instrument consists of background information (6 items), academic performance ( 1 item), adaptive performance (1 item), and 112 items of eight syndrome scales (Achenbach, 1991). This instrument designed for self-administration for teachers or other school staffs that have interaction with children. Teachers should refer to the last two months history of children`s behavior to completed the test for all scales.

\subsection{Statistic}

Results of the present study achieved by comparing the pre-test, post-test and follow-up. In this study repeated measure ANOVA was applied in order to compare the three levels of assessment. Moreover, a between, within Analysis ANOVA was conducted for the present study to evaluate effectiveness of time*group condition.

\section{Results}

\subsection{Pre-treatment Condition of the Groups}

In order to examine the baseline information of two comparison groups an independent sample t-test and Mann-Whiney test was implemented. Outcomes demonstrated that there is no significant difference between experimental and control groups in terms of ADHD symptoms, including inattention, hyperactivity/impulsivity. As a results, both groups are equivalent before commencement of the study. Results of t-test showed that the two groups don't significantly differ in attention, hyperactivity/impulsivity and ADHD symptoms in parent and teacher questionnaire, parents and children's age. Please see table 1 for a summary of information. Results of Mann-Whitney test revealed no significant difference in socioeconomic, $\mathrm{Z}=-1.42, P=>.05$, education level for children, $\mathrm{Z}=-.55, P=>.05$, education level for parents, $\mathrm{Z}=-.12, P=>.05$, gender of children, $\mathrm{Z}=-.8, P$ $=>.05$ and job condition of the parent $\mathrm{Z}=-.74, P=>.05$.

In order to achieve the differences in baseline information from children's symptom t-test was conducted. Parent report about symptoms demonstrated no significant difference between inattention, $\mathrm{t}=-.56, \mathrm{p}>.05$, hyperactivity/impulsivity $\mathrm{t}=.12, P>.05$, ADHD, $\mathrm{t}=-.76, P>.05$. Similar results achieved by report of teachers for baseline scores of inattention, $\mathrm{t}=.46, P>.05$, hyperactivity /impulsivity, $\mathrm{t}=-.37, P>.05$, and ADHD, $\mathrm{t}=.16$, $\mathrm{P}>.05$.

Table 1. Comparison of group characteristics in study samples

\begin{tabular}{|c|c|c|c|c|c|}
\hline & $\begin{array}{l}\text { Experimental G } \\
\mathrm{N}=32 \\
\mathrm{M}(\mathrm{SD})\end{array}$ & $\begin{array}{l}\text { Control G } \\
n=32 \\
M(S D)\end{array}$ & $\mathrm{t}$ & $\mathrm{z}$ & $\mathrm{p}$ \\
\hline \multicolumn{6}{|l|}{ Children } \\
\hline Age & $9.8(.81)$ & $9.9(.82)$ & -.31 & & ns \\
\hline Gender & $1.3(.47)$ & $1.5(.5)$ & & -.8 & $\mathrm{~ns}$ \\
\hline Educational level & 2.04(.7) & $1.5(.5)$ & & -.55 & ns \\
\hline \multicolumn{6}{|l|}{ Parent } \\
\hline Age range & $1.7(.8)$ & $1.8(.7)$ & -.50 & & ns \\
\hline Educational level & $2.1(.71)$ & $1.5(.51)$ & & -.12 & ns \\
\hline Job condition & $1.5(.51)$ & $1.5(.53)$ & & -.74 & ns \\
\hline Socio-economy & $3.1(.8)$ & $2.5(.5)$ & & -1.42 & ns \\
\hline \multicolumn{6}{|l|}{ CSI4-Pre-test } \\
\hline Inattention & $8.8(.79)$ & $8.9(.88)$ & -.56 & & $\mathrm{~ns}$ \\
\hline Hyperactivity/impulsivity & $7.7(1.1)$ & $8.1(.93)$ & -1.2 & & ns \\
\hline ADHD & $15.6(1.6)$ & $15.9(1.5)$ & -.76 & & ns \\
\hline \multicolumn{6}{|l|}{ TRF-Pre-test } \\
\hline Inattention & $22.5(1.5)$ & $22.3(1.7)$ & .46 & & ns \\
\hline Hyperactivity/impulsivity & $19(1.8)$ & $19.1(1.4)$ & -.37 & & ns \\
\hline ADHD & $41.5(2.5)$ & $41.4(2.1)$ & .16 & & ns \\
\hline
\end{tabular}

Note: $\mathrm{M}=$ mean, $\mathrm{SD}=$ Standard deviation, $\mathrm{Z}=$ Mann-Whitney, $\mathrm{t}=\mathrm{t}$-test. $\mathrm{P}=$ significant value, $\mathrm{ns}=$ not significant, $\mathrm{Pre}=$ pre-test, CSI $4=$ Children Symptom Inventory, $\mathrm{TRF}=$ Teacher Report Form 


\subsection{Post-treatment Condition of the Groups}

Results from one way repeated measure ANOVA for parent's report regarding children `s ADHD symptoms illustrated in Table 2. The scores in CSI4 indicated in three symptoms including inattention, hyperactivity/impulsivity. Results demonstrated significant improvement in in their children's behavior across pre-test, post-test and follow-up. According to parent's report in CSI4 inattention $[\mathrm{F}(1,62)=65.84, \mathrm{p}=.000]$ hyperactivity/impulsivity $[\mathrm{F}(1,62)=66.96, \mathrm{p}=.000]$ and $\operatorname{ADHD}[\mathrm{F}(1,62), \mathrm{p}=.000]$. Converse to results achieved form parents in experimental group, results from CSI4 in control group illustrated no significant different in attention, hyperactivity/impulsivity and DAHD results across pre-test, post-test and follow-up.

Another group of results belong to teacher's report of TRF that illustrated in Table 3 Similar results to parents achieved for teachers in experimental group regarding inattention $[\mathrm{F}(1,62)=106.16 \mathrm{p}=.000]$ hyperactivity $[\mathrm{F}$ $(1,62)=59.14 \mathrm{p}=.000]$ and $\operatorname{ADHD}[\mathrm{F}(1,62)=160.85, \mathrm{p}=.000]$ across three times level of pre-test, post-test and follow-up.

Table 2. Results of one way repeated measure ANOVA for parent report (CSI4)

\begin{tabular}{llllllll}
\hline \multirow{2}{*}{ Group } & \multirow{2}{*}{ Scale } & Pre-test & Post-test & Follow & up & \multirow{2}{*}{$\mathrm{F}$} & $\mathrm{p}$ \\
& & $\mathrm{M}(\mathrm{SD})$ & $\mathrm{M}(\mathrm{SD})$ & $\mathrm{M}(\mathrm{SD})$ & & & \\
\hline \multirow{3}{*}{ Experimental } & Inattention & $7.9(.16)$ & $5.7(.24)$ & $4.5(.24)$ & & 65.84 & 000 \\
& Hyperactivity/impulsivity & $7.8(1.02)$ & $4.53(1.6)$ & $4.96(1.5)$ & 66.96 & 000 \\
& ADHD & $15.7(1.5)$ & $10.2(2.4)$ & $9.6(2.2)$ & 86.72 & 000 \\
& Inattention & $7.6(.15)$ & $7.7(.13)$ & $7.4(.17)$ & .83 & .44 \\
\multirow{3}{*}{ Control } & Hyperactivity/impulsivity & $8.0(.84)$ & $7.8(.78)$ & $7.8(.62)$ & .739 & .48 \\
& ADHD & $15,6(1.1)$ & $15.4(1.2)$ & $15.2(1.2)$ & 1.33 & .228 \\
\hline
\end{tabular}

According to teachers report in control group, there is no significant difference between inattention, hyperactivity/impulsivity and ADHD scores across pre-test, post-test and follow-up.

Table 3. Results of one way repeated measure ANOVA for teacher report (TRF)

\begin{tabular}{llllllll}
\hline \multirow{2}{*}{ Group } & \multirow{2}{*}{ Scale } & Pre-test & Post-test & Follow & up & \multirow{2}{*}{$\mathrm{F}$ (SD) } & p \\
& & M(SD) & M(SD) & & & \\
\hline \multirow{3}{*}{ Experimental } & Inattention & $22.71(1.35)$ & $17.59(1.72)$ & $17.3(2.49)$ & 106.16 & 000 \\
& Hyperactivity/impulsivity & $19.28(1.92)$ & $16.81(2.42)$ & $15.21(2.16)$ & 59.14 & 000 \\
& ADHD & $42(2.44)$ & $34.71(3.9)$ & $32.50(3.0)$ & 160.85 & 000 \\
& Inattention & $22.28(1.63)$ & $21.50(2.49)$ & $21.46(2.38)$ & .942 & .405 \\
\multirow{3}{*}{ Control } & Hyperactivity/impulsivity & $19.37(1.50)$ & $19.65(2.86)$ & $18.81(2.57)$ & .739 & .48 \\
& ADHD & $41.65(1.87)$ & $41.12(4.23)$ & $40.87(2.80)$ & 1.66 & .206 \\
\hline
\end{tabular}

In the next step post hoc comparison was conducted (Table 4). Results demonstrated that there is significant difference between pre-test to post-test and follow-up and post-test to follow-up for inattention, hyperactivity/impulsivity and ADHD, although the results showed no significant difference between post-test to follow-up for hyperactivity/impulsivity score in parent's report in CSI4.

All results from TRF indicated to significant difference between pre-test to post-test and follow-up.

In order to determine whether dependent variables in two applied scales including CSI4 and TRF showed improvement in symptoms of children with ADHD across home and school settings, 2 (Group) 3 (time) ANOVAs with repeated measure was conducted. A significant Group_ Time interaction effect was found, indicating that children who their teachers were under treatment in contrast to the children whose teachers haven't received any treatment showed significant reduction in inattention $(F(3,62)=46.69, \mathrm{p}=.001)$, hyperactivity/impulsivity $(\mathrm{F}(3,62)=43.96, \mathrm{p}=.001$, and $\operatorname{ADHD}(\mathrm{F}(3,62)=62.98, \mathrm{p}=.001)$ in CSI4 scale. 
Table 4. Mean comparison between pre-test, post-test and follow-up within experimental group for CSI4

\begin{tabular}{|c|c|c|c|c|c|}
\hline Factor 1 & (i)time & (J) Group & Mean Difference (I-J) & Std. Error & $P$ \\
\hline \multirow{3}{*}{ Inattention } & \multirow{2}{*}{ Pre-test } & Post-test & 1.51 & .17 & .000 \\
\hline & & Follow-up & 1.84 & .27 & .000 \\
\hline & Post-test & Follow-up & .32 & .23 & .167 \\
\hline \multirow{3}{*}{ Hyperactivity/impulsivity } & \multirow{2}{*}{ Pre-test } & Post-test & 3.28 & .35 & .000 \\
\hline & & Follow-up & 2.84 & .29 & .000 \\
\hline & Post-test & Follow-up & -.438 & .38 & .256 \\
\hline \multirow{3}{*}{ ADHD } & \multirow{2}{*}{ Pre-test } & Post-test & 5.46 & .51 & .000 \\
\hline & & Follow-up & 6.09 & .46 & .000 \\
\hline & Post-test & Follow-up & .625 & .40 & .129 \\
\hline
\end{tabular}

Table 5. Mean comparison between pre-test, post-test and follow-up within experimental group for TRF

\begin{tabular}{|c|c|c|c|c|c|}
\hline Factor 1 & (i)time & (J) Group & Mean Difference (I-J) & Std. Error & $\boldsymbol{P}$ \\
\hline \multirow{3}{*}{ Inattention } & \multirow{2}{*}{ Pre-test } & Post-test & 5.12 & .56 & .000 \\
\hline & & Follow-up & 5.37 & .42 & .000 \\
\hline & Post-test & Follow-up & .250 & .66 & .109 \\
\hline \multirow{3}{*}{ Hyperactivity/impulsivity } & \multirow{2}{*}{ Pre-test } & Post-test & 2.47 & .42 & .000 \\
\hline & & Follow-up & 4.15 & .39 & .000 \\
\hline & Post-test & Follow-up & 1.69 & .47 & .001 \\
\hline \multirow{3}{*}{ ADHD } & \multirow{2}{*}{ Pre-test } & Post-test & 7.28 & .75 & .000 \\
\hline & & Follow-up & .955 & .54 & .000 \\
\hline & Post-test & Follow-up & 2.21 & .80 & .010 \\
\hline
\end{tabular}

Moreover, children demonstrated significant reduction in their main symptoms including inattention, $(\mathrm{F}(3,62)=$ $42.28, \mathrm{p}=.001)$, hyperactivity/impulsivity $(\mathrm{F}(3,62)=23.55, \mathrm{p}=.001)$ and $\operatorname{ADHD}(\mathrm{F}(3,64)=84.64, \mathrm{p}=.001)$ in TRF scale that completed by teachers.

Table 6. Two way repeated measure ANOVA for inattention, hyperactivity/impulsivity and ADHD in CSI4 and TRF

\begin{tabular}{llll}
\hline \multirow{2}{*}{ Scale } & & $\begin{array}{l}\text { Group } \times \text { time } \\
\text { interaction }\end{array}$ & $\mathrm{p}$ \\
\hline \multirow{3}{*}{ CSI4 } & Inattention & 46.69 & .000 \\
& Hyperactivity/impulsivity & 43.96 & .000 \\
& ADHD & 62.98 & .000 \\
\multirow{3}{*}{ TRF } & Inattention & 42.28 & .000 \\
& Hyperactivity/impulsivity & 23.55 & .000 \\
& ADHD & 84.64 & .000 \\
\hline
\end{tabular}

\section{Discussion}

Purpose of the present study was to evaluate the effectiveness of school-based multi-component intervention on symptoms of children with ADHD. Present study applied experimental randomized control pre-test, post-test design. The effectiveness of the program was examined by measuring the changes in children's inattention, hyperactivity/impulsivity and ADHD symptoms across home and school settings from pre-test to post-test and follow-up. In the present study it was hypothesized that all teachers who received teacher intervention would report a reduction in mentioned symptoms of children with ADHD and parents who just received some general information regarding ADHD children would report no or small reduction in symptoms. The results of this study confirmed the first hypothesis regarding teacher's reports for ADHD symptoms by TRF in experimental group. 
In spite of our hypothesis regarding parental report, results from CSI4 showed reduction in all three symptoms of ADHD. This indicated that eight sessions of school-based multi-component intervention in school is effective in decreasing the main symptoms of ADHD at home that shows the generalization of this program from school to other social context.

Findings of the present study are consistence with previous research outcomes (Miranda et al., 2002; Miranda, Herrero, Hierro, \& Jiménez, 2013). Previous study by Miranda et al. (2002) showed improvement in primary symptoms and other behavioral difficulties associated with ADHD children such as antisocial behavior, internalizing behaviors and anxiety that detected by parents. Although the study by Miranda et al. (2002) demonstrated some improvements in somatic problems in control group that may be attributed to factors beyond the treatment. Similarly, present study demonstrated considerable improvement in main symptoms of children with ADHD. Other aspects of ADHD children weren't in scope of the present study. Parents and teacher's rating showed no significant effect of the treatment on children in control group.

Similar to study by Miranda et al. (2002) in the present study teachers reported significant reduction in symptoms of children with ADHD. These outcomes were confirmed by achieved information from class observation regarding inattention, hyperactivity/impulsivity and ADHD. Moreover this information was completed by a semi-structured interview by teachers that determined some reasons for improvement of symptoms and other fields of activities of ADHD children in classroom.

One of the main factors that mentioned by teachers was group format of the intervention that provided a face to face interactions between teachers in the treatment session. In fact, treatment sessions for teachers provided an opportunity to know about all aspects of ADHD problems in class by sharing their experiences and anticipating the outcomes of the treatment in their class.

All teachers also indicated for enhancing their knowledge regarding ADHD and management skills for these children in the class. Received information regarding ADHD symptoms during treatment sessions helped teachers to be aware how to interact with ADHD children in the class. Other sources of information, class observation and interview by teachers, showed increasing level of educational achievement in the class by ADHD children. Children in the class showed better attention span and academic performance than children in control group that make the findings of this study more valuable as these improvements usually is difficult to achieve by stimulant medication (Rapport, Denney, DuPaul, \& Gardner, 1994). Moreover, the present study is in line with the study by Miranda et al. (2013) that confirm improvement of main symptoms of children with ADHD. Both studies applied parent and teacher ratings.

Based on previous studies, there are different assumptions regarding effectiveness of cognitive-based intervention for ADHD children that highlight a dire need for further outcomes. This study provided document for effectiveness of cognitive behavioral intervention on ADHD symptoms. The applied methodology and particular component of the program showed effective outcomes for the study. Also, this study confirmed the previous outcomes for cognitive interventions for ADHD children by showing similar results after three months of follow-up (Klingberg et al., 2005).

Another theory that has applied in the present study was instructional management in classroom. This study is comparable with previous study by Imeraj et al. (2013) that applied instructional context in classroom for ADHD and non ADHD children. Results of this study showed that, although the on-task behavior of children after treatment improved, children with ADHD demonstrated lower on-task, self-regulation and planning behavior rather those non-ADHD children. The achieved information by a supervision psychologist illustrated the effectiveness of the treatment in the present study on on-task and on-task span for ADHD children in the class as there is no non-ADHD children in this study group to make the results comparable.

Another study addressed the effectiveness of teacher training on ADHD and ODD symptoms (Froelich, Breuer, Doepfner, \& Amonn, 2012). Results of the mentioned study showed considerable reduction in ADHD and ODD symptoms from baseline to after treatment. Stated study applied a non-randomized control group and a within subject control group design. This study applied a clear instruction for teachers that are similar with applied school-based multi-component intervention in the present study. Another similarity of these two studies is applying the concrete questionnaires.

Based on semi-structured interview and the teachers feedback during sessions, school-based multi-component intervention is a comprehensive program that focuses on different aspects of children's problem in the class. Moreover, teachers mentioned that this program is suitable for all students in class. Another positive trait related to the program that was mentioned by teachers was that the program is easy to handle with low time and cost. Generally speaking the effectiveness of school-based multi-component intervention is manifold as it is applying 
different theories based on symptoms of these children. This intervention focused on various variables that cause ADHD behavioral, social and academic problems. These unique and comprehensive features of the intervention lead to a symptom reduction across home and school settings. The results of the study demonstrated the importance of school as a main setting in children's life and this study showed generalization of school outcomes to children's behavior at home. Moreover, methodological design of the present study and particular components of the program provide an appropriate model for working with ADHD children.

One of the main contributions of the present study was the new method for teachers in Iran who are enthusiastic in working with ADHD children. This intervention can be a guideline for all school counselors to be as a trainer for teachers. Although, this study needs to be replicated with focusing on other aspects of problems of children with ADHD. This study has several limitations that should be considered. Firstly, the program in the present study applied once a week and lasts eight weeks, although the original version of this program should be implemented every two weeks and finish in four months. These changes may create different outcomes. Moreover, as the main focus of the present study was ADHD symptoms in the class, thus the other aspects of their problems in and out of school weren't in the scope of this study. Moreover, present study implemented on children with ADHD combined type that limited the generalization of the outcomes.

\section{Acknowledgements}

We gratefully appreciate all the support and help received from numerous individuals to complete this research.

\section{References}

Achenbach, T. M. (1991). Child behavior checklist/4-18. Burlington: University of Vermont.

American Psychiatric Association. (2013). Diagnostic and Statistical Manual of Mental Disorders: Dsm-5 (5th ed.). Washington, DC: Amer Psychiatric Pub Incorporated. http://dx.doi.org/10.1176/appi.books.9780890 425596

Atkins, M. S., Graczyk, P. A., Frazier, S. L., \& Abdul-Adil, J. (2003). Toward A New Model for Promoting Urban Children's Mental Health: Accessible, Effective, and Sustainable School-Based Mental Health Services. School Psychology Review.

Barkley, R. A. (2000). Taking charge of ADHD: The complete, authoritative guide for parents. The Guilford Press.

Barkley, R. A. (2003). Issues in the diagnosis of attention-deficit/hyperactivity disorder in children. Brain and Development, 25(2), 77-83. http://dx.doi.org/10.1016/S0387-7604(02)00152-3

Biederman, J., Petty, C., Dolan, C., Hughes, S., Mick, E., Monuteaux, M., \& Faraone, S. (2008). The long-term longitudinal course of oppositional defiant disorder and conduct disorder in ADHD boys: Findings from a controlled 10-year prospective longitudinal follow-up study. Psychological Medicine, 38(7), 1027-1036. http://dx.doi.org/10.1017/S0033291707002668

Donnelly, M., Haby, M. M., Carter, R., Andrews, G., \& Vos, T. (2004). Cost-effectiveness of dexamphetamine and methylphenidate for the treatment of childhood attention deficit hyperactivity disorder. Australian and New Zealand Journal of Psychiatry, 38(8), 592-601. http://dx.doi.org/10.1080/j.1440-1614.2004.01422.x

Esmayil, E. M. (2001). Assessment of validity and reliability of Child Symptom Inventory (CSI4) in students between 6 to 14 year old in elementary and secondary schools of Tehran: Institute of Retarded Children.

Froelich, J., Breuer, D., Doepfner, M., \& Amonn, F. (2012). Effects of a Teacher Training Programme on Symptoms of Attention Deficit Hyperactivity Disorder. International Journal of Special Education, 27(3), 76-87.

Hodgson, K., Hutchinson, A. D., \& Denson, L. (2012). Nonpharmacological treatments for ADHD: A meta-analytic review. Journal of attention disorders. http://dx.doi.org/10.1177/1087054712444732

Hooshvar, P., Behnia, F., Khooshabi, K., Mirzayi, H., \& Rahgozar, M. (2009). Effectiveness of group parent training on behavioral disorders of children 4 to 10 year old with attention deficit-hyperactivity disorder. Journal of prehabilitation, 39(2), 24-30.

Imeraj, L., Antrop, I., Sonuga-Barke, E., Deboutte, D., Deschepper, E., Bal, S., \& Roeyers, H. (2013). The impact of instructional context on classroom on-task behavior: A matched comparison of children with ADHD and non-ADHD classmates. Journal of school psychology, 51(4), 487-498. http://dx.doi.org/10. 1016/j.jsp.2013.05.004

Khooshabi, K., \& Puretemad, H. (2002). Investigation of rate of ADHD and comorbid disorders on elementary 
students of Tehran. Research Report, for Welfare Sciences and Rehabilitation University, Tehran.

Khooshabi, K., \& Roshanbin, M. (2009). The Effectiveness of Group Positive Parenting Program on Parental Stress of Mothers of Children with Attention-Deficit/Hyperactivity Disorder. Archives of Iranian Medicine, 12(1), 60-68.

Klingberg, T., Fernell, E., Olesen, P. J., Johnson, M., Gustafsson, P., Dahlström, K., ..., Westerberg, H. (2005). Computerized training of working memory in children with ADHD-a randomized, controlled trial. Journal of the American Academy of Child \& Adolescent Psychiatry, 44(2), 177-186. http://dx.doi.org/10.1097/0000 4583-200502000-00010

Miranda, A., Herrero, M. J. P., Hierro, R. S., \& Jiménez, P. J. (2013). Effects of a psychosocial intervention on the executive functioning in children with $A D H D$.

Miranda, A., Jarque, S., \& Rosel, J. (2006). Treatment of children with ADHD: Psycho-pedagogical program at school versus psycho-stimulant medication. Psicothema, 18(3), 335-341.

Miranda, A., Presentacia, M. J., \& Soriano, M. (2002). Effectiveness of a school-based multicomponent program for the treatment of children with ADHD. Journal of learning disabilities, 35(6), 547. http://dx.doi.org/10. 1177/00222194020350060601

Miranda, A., Presentación, M. J., Siegenthaler, R., \& Jara, P. (2011). Effects of a psychosocial intervention on the executive functioning in children with ADHD. Journal of learning disabilities. http://dx.doi.org/10.1177/ 0022219411427349

Noori, M. (2010). Behavioral management and educational strategies in classroom for children with attention deficit-hyperactivity disorder. Journal of retardation nurturing and education, 103(8), 21-30.

Pelham, W. E., \& Fabiano, G. A. (2008). Evidence-based psychosocial treatments for attention-deficit/hyperactivity disorder. Journal of Clinical Child \& Adolescent Psychology, 37(1), 184-214. http://dx.doi.org/10.1080/15374410701818681

Pelham, W. E., Schnedler, R. W., Bender, M. E., Nilsson, D. E., Miller, J., Budrow, M. S., .., Marks, D. A. (1988). The combination of behavior therapy and methylphenidate in the treatment of attention deficit disorders: A therapy outcome study.

Pelham, W. E., Wheeler, T., \& Chronis, A. (1998). Empirically supported psychosocial treatments for attention deficit hyperactivity disorder. Journal of Clinical Child Psychology.

Peterson, K., McDonagh, M. S., \& Fu, R. (2008). Comparative benefits and harms of competing medications for adults with attention-deficit hyperactivity disorder: A systematic review and indirect comparison meta-analysis. Psychopharmacology, 197(1), 1-11. http://dx.doi.org/10.1007/s00213-007-0996-4

Rapport, M. D., Denney, C., DuPaul, G. J., \& Gardner, M. J. (1994). Attention deficit disorder and methylphenidate: Normalization rates, clinical effectiveness, and response prediction in 76 children. Journal of the American Academy of Child \& Adolescent Psychiatry, 33(6), 882-893. http://dx.doi.org/10. 1097/00004583-199407000-00015

\section{Copyrights}

Copyright for this article is retained by the author(s), with first publication rights granted to the journal.

This is an open-access article distributed under the terms and conditions of the Creative Commons Attribution license (http://creativecommons.org/licenses/by/3.0/). 